\title{
Phytochemical Profile and Antioxidant Properties of Italian Green Tea, a New High Quality Niche Product
}

\author{
Nicole Mélanie Falla, Sonia Demasi $\mathbb{D}$, Matteo Caser * (D) and Valentina Scariot $\mathbb{C}$ \\ Department of Agricultural, Forest and Food Sciences, University of Torino, Largo Paolo Braccini 2, \\ 10095 Grugliasco, TO, Italy; nicolemelanie.falla@unito.it (N.M.F.); sonia.demasi@unito.it (S.D.); \\ valentina.scariot@unito.it (V.S.) \\ * Correspondence: matteo.caser@unito.it; Tel.: +39-011-670-8935
}

check for updates

Citation: Falla, N.M.; Demasi, S.; Caser, M.; Scariot, V. Phytochemical Profile and Antioxidant Properties of Italian Green Tea, a New High Quality Niche Product. Horticulturae 2021, 7, 91. https://doi.org/ 10.3390/horticulturae7050091

Academic Editors: Lucia Guidi, Luigi De Bellis, Alberto Pardossi and Elazar Fallik

Received: 15 March 2021

Accepted: 23 April 2021

Published: 27 April 2021

Publisher's Note: MDPI stays neutral with regard to jurisdictional claims in published maps and institutional affiliations.

Copyright: (c) 2021 by the authors. Licensee MDPI, Basel, Switzerland. This article is an open access article distributed under the terms and conditions of the Creative Commons Attribution (CC BY) license (https:/ / creativecommons.org/licenses/by/ $4.0 /)$.
Abstract: The hot beverage commonly known as tea results from the infusion of dried leaves of the plant Camellia sinensis (L.) O. Kuntze. Ranking second only to water for its consumption worldwide, it has always been appreciated since antiquity for its aroma, taste characteristics, and beneficial effects on human health. There are many different processed tea types, including green tea, a non-fermented tea which, due to oxidation prevention maintains the structure of the bioactive compounds, especially polyphenols; these bioactive compounds show a number of benefits for the human health. The main producers of tea are China and India, followed by Kenya, Sri Lanka, Turkey, and Vietnam, however recently new countries are entering the market, with quality niche productions, among which also Italy. The present research aimed to assess the bioactive compounds (polyphenols) and the antioxidant activity of two green teas (the "Camellia d'Oro" tea-TCO, and the "Compagnia del Lago" tea-TCL) produced in Italy, in the Lake Maggiore district, where nurserymen have recently started to cultivate $C$. sinensis. In this area the cultivation of acidophilic plants as ornamentals has been known since around 1820. Due to the crisis of the floricultural sector, producers have been trying to diversify their product in order to increase their competitiveness, starting to cultivate Italian tea. Their antioxidant activity was assessed, finding a similar or higher antioxidant capacity than in other green teas, as reported in literature. TCO showed a higher antioxidant activity $\left(42,758.86 \mathrm{mmol} \mathrm{Fe}^{2+} \mathrm{kg}^{-1} ; 532.37 \mu \mathrm{mol} \mathrm{TE} \mathrm{g}{ }^{-1} \mathrm{DW} ; 881.08 \mu \mathrm{mol} \mathrm{TE} \mathrm{g}^{-1} \mathrm{DW}\right)$ and phenolic content $\left(14,918.91 \mathrm{mg}\right.$ GAE $\left.100 \mathrm{~g}^{-1} \mathrm{DW}\right)$ than TCL $\left(25,796.61 \mathrm{mmol} \mathrm{Fe}{ }^{2+} \mathrm{kg}^{-1} ; 302.35 \mu \mathrm{mol}\right.$ TE g ${ }^{-1} \mathrm{DW}$; $\left.623.44 \mu \mathrm{mol} \mathrm{TE} \mathrm{g}^{-1} \mathrm{DW} ; 8540.42 \mathrm{mg} \mathrm{GAE} 100 \mathrm{~g}^{-1} \mathrm{DW}\right)$. Through HPLC, a total of thirteen phenolic compounds were identified quantitatively, including catechins, benzoic acids, cinnamic acids, and flavonols, in TCO while only 9 in TCL, and mainly in lower amounts. Albeit with differences, both teas were found to be of quality proving that Italy could have the possibility to grow profitably C. sinensis.

Keywords: tea; Camellia sinensis; antioxidant activity; DPPH; ABTS; FRAP; HPLC

\section{Introduction}

The hot beverage resulting from the infusion of dried leaves of the plant Camellia sinensis (L.) O. Kuntze is commonly known as tea [1,2]. Tea is one of the most popular nonalcoholic beverages consumed across the world, second only to water [3-9], so much appreciated since antiquity for its aroma, taste characteristics, and beneficial health effects [1], thus consumed as an herbal infuse and for its medicinal properties [5,6]. World tea consumption increased to 5.5 million tons by 2016, mostly due to a rapid growth in per capita income levels in China, India, and other emerging economies [10]. The World Bank foresees an increase in average tea auction price from USD 2.80 in 2017 to USD 2.84 in 2020, expecting an extension of the global tea market [11]. World tea production reached 5.73 million tons in 2016 [10], with China constituting of $42.6 \%$ of world tea production [10], accounting for USD 4 billion [12]. India, the second largest producer, recorded a production of 1.27 million tons in 2016. 
There are many different types of teas, and most of them are prepared with the buds of two botanical varieties, C. sinensis var. sinensis and C. sinensis var. assamica (Masters) Wight $[9,13]$; their characteristics (i.e., appearance, organoleptic taste, chemical contents, and flavor) vary according to the fermentation level: tea can be categorized in nonfermented tea (i.e., green tea, and white tea), semifermented tea (i.e., oolong tea), and fermented tea (i.e., black tea and red tea) $[5,6,9,14-17]$. The $78 \%$ of the tea worldwide production is black tea, especially consumed in Western countries, $20 \%$ consists of green tea, which is usually consumed in Asian countries, and $\%$ regards Oolong tea, commonly consumed in southern China [14]. Globally, the production of green tea increased annually by $5.4 \%$ over the past decade, also due to green tea's perceived health benefits [10].

Actually, fresh tea leaves contain chemical components such as polyphenols (catechins, flavonoids), alkaloids (caffeine, theobromine, etc.), volatile oils, polysaccharides, amino acids, lipids, vitamins (e.g., vitamin C), etc. $[6,9,18]$. Green teas are produced through steaming or roasting, thus inactivating the activity of polyphenol oxidase, preventing oxidation and so maintaining the structure of the phenolic compounds $[1,5,18]$. The resulting green teas show a polyphenol content varying from $30 \%$ to $42 \%$ of dry matter weight [14].

Due to its chemical constituents, tea shows many beneficial properties, such as antioxidant, anti-inflammatory, antiallergic, anticarcinogenic, antidiabetic, and antimicrobial effects $[6,7,9,14,15,19-21]$. A regular, daily consumption of green tea has been associated with many health benefits [7,22], which are mainly attributed to polyphenols, especially catechins $[3,9,23]$.

Khan and Mukhtar (2007) reported that a balanced diet and the consumption of green tea can protect from oxidative stress and reduce reactive oxygen species damages to lipid membranes, proteins, and nucleic acids.

Moreover, many epidemiological studies investigated how tea consumption affected the incidence of cancer in humans, finding a protective and preventive effect of tea against various types of cancer (oral, pharyngeal, and laryngeal cancer) [14], but also healthy effects on many other pathologies involving oxidative stress.

Today, more than 50 countries produce different types of tea worldwide, not only as an herbal infuse pleasant to consume, but also for its well-known benefits on human health $[2,5]$.

Tea evergreen plant (C. sinensis) $[3,4]$ is native to South and Southwest China, the Indian Subcontinent, and Southeast Asia [2,24,25], then it became popular in India and Japan, and later in Europe and Russia [5,6]. The first plant specimens arrived in Europe were those studied by Linnaeus in 1763 [26], although the tea beverage had already reached Europe in the XVII century. However, tea cultivation has remained a prerogative of Asian countries, while in Europe the cultivation of the congeneric species Camellia japonica has spread for ornamental purposes only. The first camellia (C. japonica) was introduced in Italy at the end of the XVII century, in Caserta (Campania, South Italy) [27,28]. Since then its cultivation gradually became popular, reaching central and northern Italy, especially Tuscany, Piedmont, and Lombardy [27].

The critical period of the floricultural sector caused by globalization $[27,29]$, since the end of the past decade forced Italian producers of the Lake Maggiore district (Piedmont region) to diversify their final products in order to increase their competitiveness, starting to cultivate $C$. sinensis in order to produce Italian green tea.

Currently there are no studies related to the quality of tea produced in Italy, thus, the aim of the present research was to assess the main bioactive compounds (polyphenols), and beneficial properties (antioxidant activity) of two green teas produced in this new productive context. 


\section{Materials and Methods}

\subsection{Plant Material and Site Characteristics}

Camellia sinensis var. sinensis dried leaves were kindly provided by "La Compagnia del Lago" and "La Camelia d'Oro" plantations, both located in the Lake Maggiore area, in Piedmont-North Italy. Seedlings of camellia derived from acclimatization specimen from parks and botanical gardens located in the Lake Maggiore area (i.e., Villa Taranto, Isola Madre and Villa Anelli, Verbania municipality, Piedmont region), and were grown differently in the two nurseries. The "Compagnia del Lago" plantation is located in the municipality of Premosello Chiovenda (VB) $\left(45^{\circ} 55^{\prime} 57.6^{\prime \prime} \mathrm{N} 8^{\circ} 27^{\prime} 16.1^{\prime \prime} \mathrm{E}\right)$, where the annual average maximum temperature was $19.8^{\circ} \mathrm{C}$ (July showed the highest monthly average temperature, with $30.6^{\circ} \mathrm{C}$ ), the annual average minimum temperature was $7.8^{\circ} \mathrm{C}$ (January showed the lowest monthly average temperature, with $-3.6^{\circ} \mathrm{C}$ ), and the annual average rainfall was $122.8 \mathrm{~mm}$ (March showed the highest monthly average rainfall, with $279.0 \mathrm{~mm}$, while October showed the lowest monthly average rainfall, with $0.0 \mathrm{~mm}$ ) for the investigation year 2017 (Figure 1). The seedlings were planted in the ground at a distance of $2.20 \mathrm{~m}$ in the row, in a stony sloping terrain, managed as a meadow for more than a century. Irrigation was made by drip-wing system when occurred. The plants were not fertilized.
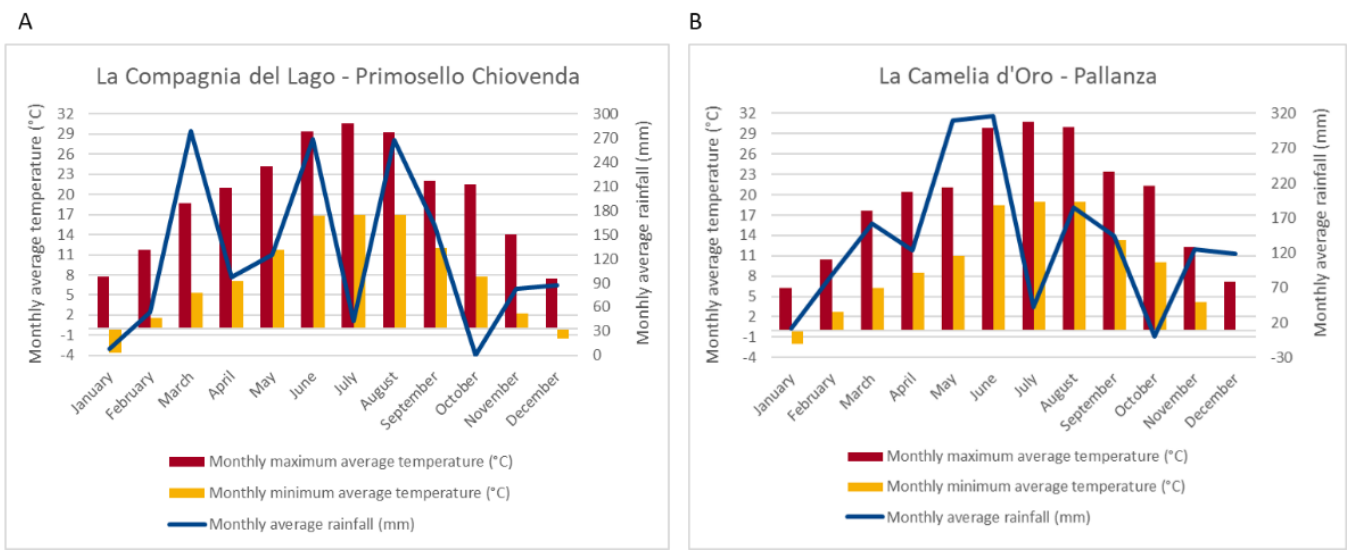

Figure 1. Monthly average temperatures (maximum and minimum $-{ }^{\circ} \mathrm{C}$ ), and monthly average rainfall (mm) for the investigation year 2017 in: (A). the "Compagnia del Lago" site of cultivation. (B). the "Camelia d'Oro" site of cultivation.

The "Camelia d'Oro" plantation is located in Pallanza (VB) $\left(45^{\circ} 56^{\prime} 47.9^{\prime \prime} \mathrm{N} 8^{\circ} 35^{\prime} 12.6^{\prime \prime} \mathrm{E}\right)$, where the annual average maximum temperature was $19.2^{\circ} \mathrm{C}$, the annual average minimum temperature was $9.2{ }^{\circ} \mathrm{C}$, and the annual average rainfall was $135.6 \mathrm{~mm}$ for the investigation year 2017 (Figure 1). Here, before planting the seedlings, the soil was tilled with a milling cutter and a bottom fertilization with organic manure burial powder (Humus Vita, Fomet Spa, San Pietro di Morubio (VR), Italy) (25 kg per $100 \mathrm{~m}^{2} . \mathrm{N}, \mathrm{P}$, and K were all present as $3-4 \%$ of the total amount, accounting on average for $8.75 \mathrm{~g}$ of each per $\mathrm{m}^{2}$. Organic matter accounted for $38-45 \%$, thus on average $103.75 \mathrm{~g}$ per $\mathrm{m}^{2}$ of it were added.) was made. The plants were transferred to the ground, at a distance of $0.8 \mathrm{~m}$ in a row and $1.2 \mathrm{~m}$ in the inter-row, resulting in 1 plant per $\mathrm{m}^{2}$. The hole in the ground was made with a drill and 2.5 $\mathrm{L}$ of Blond peat were added to each plant as a soil improver. The plants were tamped down and mulched with an organic mulching consisting in a mix of wood chips and leaves. In May, a cover fertilization with an organic ox-blood fertilizer (10 cc per plant) (Biostan, Aifar Agrochimica Srl, Ronco Scrivia (GE), Italy) was performed. Plants were irrigated with drip-wing irrigation with about $1.6 \mathrm{~L}$ of water per plant per day.

\subsection{Tea Harvest and Preparation}

In both plantations, fresh tea shoots with one (late spring or September harvest) or two (spring harvest between late April and early May) tender leaves and a bud were harvested. 
After harvesting, tea leaves were steamed for about 1-2 min; once dried, the leaves were roasted and rolled on a hot pan at about $80^{\circ} \mathrm{C}$ for about $10-15 \mathrm{~min}$ to stop the fermentation. They were then left in a dryer at $40^{\circ} \mathrm{C}$ for $18 \mathrm{~h}$, and finally stored in plastic containers at room temperature.

Thus, green teas were obtained from dried leaves received from: "La Camelia d'Oro" plantation (TCO-Tea Camellia d'Oro), providing us with samples of one shoot with one leaf (first harvest), and "La Compagnia del Lago" plantation (TCL-Tea Compagnia del Lago), providing us with a mixture of the two harvests.

\subsection{Tea Extract Preparation}

The dried leaves were ground with a mortar and pestle into a fine powder. Two hundred milliliter of deionized water was heated to $100^{\circ} \mathrm{C}$. One gram of dried tea leaves powder was added to the cooling water and left to infuse for $10 \mathrm{~min}$, being stirred every two minutes. The infusion was filtered with paper filters (Whatman filter papers No. 1, Whatman, Maidstone, UK), and then with polytetrafluoroethylene (PTFE, VWR International, Milano, Italy) filters, with a $25 \mathrm{~mm}$ diameter and $0.45 \mu \mathrm{m}$ pore size.

Both infusions were diluted with deionized water to obtain the working solution and maintained at $-20{ }^{\circ} \mathrm{C}$ for the following analysis.

\subsection{Bioactive Compounds}

\subsubsection{Total Polyphenols}

The total phenolic content of diluted TCL (dilution 1:1 $=1 \mathrm{~mL}$ deionized water: $1 \mathrm{~mL}$ infusion) and TCO (dilution 1:2 $=1.2 \mathrm{~mL}$ deionized water: $600 \mu \mathrm{L}$ infusion) was determined following the Folin-Ciocalteu method, as indicated by Singleton et al. [30]. The analysis was performed as follows: $1000 \mu \mathrm{L}$ of diluted 1:10 Folin reagent were mixed with $200 \mu \mathrm{L}$ of infusion in each plastic tube. The samples were left in the dark at room temperature for 10 min, then $800 \mu \mathrm{L}$ of $\mathrm{Na}_{2} \mathrm{CO}_{3}(7.5 \%)$ were added to each tube. Samples were left in the dark at room temperature for $30 \mathrm{~min}$. Absorbance was then measured at $765 \mathrm{~nm}$ by means of a spectrophotometer (Cary 60 UV-Vis, Agilent Technologies, Santa Clara, CA, USA), and the results were expressed in milligrams of gallic acid equivalents per $100 \mathrm{~g}$ of dry weight $(\mathrm{mg}$ GAE $\left.100 \mathrm{~g}^{-1} \mathrm{DW}\right)$. Analysis was performed in six replicates per infusion type.

\subsubsection{Antioxidant Activity \\ FRAP Assay}

The first procedure adopted to evaluate the antioxidant activity of diluted TCL $(1: 2=1.2 \mathrm{~mL}$ deionized water: $600 \mu \mathrm{L}$ infusion $)$ and TCO $(1: 3=1.5 \mathrm{~mL}$ deionized water: $500 \mu \mathrm{L}$ infusion) was the ferric ion reducing antioxidant power (FRAP) method [31].

The FRAP solution was obtained by mixing a buffer solution at $\mathrm{pH} 3.6$ $\left(\mathrm{C}_{2} \mathrm{H}_{3} \mathrm{NaO}_{2} * 3 \mathrm{H}_{2} \mathrm{O}+\mathrm{C}_{2} \mathrm{H}_{4} \mathrm{O}_{2}\right.$ in water), 2,4,6-tripyridyltriazine (TPTZ, $10 \mathrm{mM}$ in $\mathrm{HCl}$ $40 \mathrm{mM})$, and $\mathrm{FeCl}_{3}{ }^{*} 6 \mathrm{H}_{2} \mathrm{O}(20 \mathrm{mM})$.

The antioxidant activity was determined mixing $30 \mu \mathrm{L}$ of diluted infusion with $90 \mu \mathrm{L}$ of deionized water and $900 \mu \mathrm{L}$ of FRAP reagent. The samples were then placed at $37^{\circ} \mathrm{C}$ for $30 \mathrm{~min}$. Absorbance was measured at $595 \mathrm{~nm}$ by means of a spectrophotometer (Cary 60 UV-Vis, Agilent Technologies, Santa Clara, CA, USA). The antioxidant activity was plotted against a $\mathrm{FeSO}_{4}{ }^{*} 7 \mathrm{H}_{2} \mathrm{O}$ calibration curve. Extraction solution (water) without infusion was used as a control sample. Results were expressed as millimoles of ferrous iron equivalents per kilogram $\left(\mathrm{mmol} \mathrm{Fe} \mathrm{Fg}^{2+} \mathrm{kg}^{-1} \mathrm{DW}\right)$. Analysis was performed in six replicates per infusion type.

\section{DPPH Assay}

The second procedure was the 2,2-diphenyl-1-picrylhydrazyl (DPPH) radical scavenging method [32].

The working solution of DPPH radical cation $\left(\mathrm{DPPH}^{\circ}, 100 \mu \mathrm{M}\right)$ was obtained by dissolving $2 \mathrm{mg}$ of DPPH in $50 \mathrm{~mL}$ of $\mathrm{MeOH}$. The solution must have an absorbance of 
$1000( \pm 0.05)$ at $515 \mathrm{~nm}$. To prepare the samples, $40 \mu \mathrm{L}$ of diluted infusion were mixed with $3 \mathrm{~mL}$ of DPPH. Samples were then left in the dark at room temperature for $30 \mathrm{~min}$. Absorbance was measured at $515 \mathrm{~nm}$ by means of a spectrophotometer (Cary $60 \mathrm{UV}$-Vis, Agilent Technologies, Santa Clara, CA, USA). The DPPH radical-scavenging activity was calculated as:

$$
[(\operatorname{Abs} 0-\operatorname{Abs} 1) / \operatorname{Abs} 0] \times 100
$$

where Abs0 is the absorbance of the control (extraction solution without infusion) and Abs1 is the absorbance of the sample. The antioxidant capacity was plotted against a Trolox calibration curve and results were expressed as $\mu \mathrm{mol}$ of Trolox equivalents per gram of dry weight ( $\mu \mathrm{mol}$ TE g-1 DW). Analysis was performed in six replicates per infusion type.

\section{ABTS Assay}

The third procedure was the 2,20-azino-bis-(3-ethylbenzothiazoline-6-sulphonic acid) (ABTS) method [33].

The working solution of ABTS radical cation (ABTS) was obtained by the reaction of $7.0 \mathrm{mM}$ ABTS stock solution with $2.45 \mathrm{mM}$ potassium persulfate $\left(\mathrm{K}_{2} \mathrm{~S}_{2} \mathrm{O}_{8}\right)$ solution. After incubating for $12-16 \mathrm{~h}$ in the dark at room temperature, the working solution was diluted with distilled water to obtain an absorbance of $0.7( \pm 0.02)$ at $734 \mathrm{~nm}$. The antioxidant activities of the diluted TCL (1:2) and TCO (1:3) infusions were assessed mixing $30 \mu \mathrm{L}$ of infusion with $2 \mathrm{~mL}$ of diluted ABTS. The samples were left in the dark for $10 \mathrm{~min}$. Absorbance was then measured at $734 \mathrm{~nm}$ by means of a spectrophotometer (Cary $60 \mathrm{UV}$ Vis, Agilent Technologies, Santa Clara, CA, USA). The ABTS radical-scavenging activity was calculated as:

$$
[(\mathrm{Abs} 0-\mathrm{Abs} 1) / \mathrm{Abs} 0] \times 100
$$

where Abs0 is the absorbance of the control (extraction solution without infusion) and Abs1 is the absorbance of the sample. The antioxidant capacity was plotted against a Trolox calibration curve and results were expressed as $\mu \mathrm{mol}$ of Trolox equivalents per gram of dry weight ( $\mu \mathrm{mol} \mathrm{TE} \mathrm{g-1} \mathrm{DW).} \mathrm{Analysis} \mathrm{was} \mathrm{performed} \mathrm{in} \mathrm{six} \mathrm{replicates} \mathrm{per} \mathrm{infusion} \mathrm{type.}$

\subsubsection{Identification and Quantification of Bioactive Compounds by HPLC}

The bioactive compounds contained in the infusions were determined by means of two high performance liquid chromatography-diode array detection (HPLC-DAD) method [34], using an Agilent 1200 High-Performance Liquid Chromatograph coupled to an Agilent UV-Vis diode array detector (Agilent Technologies, Santa Clara, CA, USA). Detailed chromatographic methods are reported in Table 1. Phytochemical separation was performed with a Kinetex C18 column $(4.6 \times 150 \mathrm{~mm}, 5 \mu \mathrm{m}$, Phenomenex, Torrance, CA, USA), using different mobile phases for compound identification and recording of UV spectra at different wavelengths, based on HPLC methods, as previously tested and validated $[35,36]$ with some modifications. UV spectra were recorded at $330 \mathrm{~nm}$ and $280 \mathrm{~nm}$. The following bioactive compounds were determined: cinnamic acids (caffeic acid, chlorogenic acid, coumaric acid, ferulic acid), flavonols (hyperoside, isoquercitrin, quercetin, quercitrin, rutin), benzoic acids (ellagic acid, gallic acid), catechins (catechin, epicatechin). All single compounds were identified by a comparison and combination of their retention times and UV spectra with those of authentic standards under the same chromatographic conditions. Results were expressed as $\mathrm{mg} 100 \mathrm{~g}^{-1}$ of dry weight (DW). 
Table 1. HPLC methods and relative chromatographic conditions.

\begin{tabular}{|c|c|c|c|c|}
\hline Method & Classes of Interest & Stationary Phase & Mobile Phase & Wavelength $(\mathrm{nm})$ \\
\hline A & $\begin{array}{l}\text { Cinnamic acids } \\
\text { Flavonols }\end{array}$ & $\begin{array}{l}\text { KINETEX-C18 column } \\
(4.6 \times 150 \mathrm{~mm}, 5 \mu \mathrm{m})\end{array}$ & $\begin{array}{c}\mathrm{A}: 10 \mathrm{mM} \mathrm{KH} \mathrm{PO}_{4} / \mathrm{H}_{3} \mathrm{PO}_{4} \\
\mathrm{pH}=2.8 \\
\mathrm{~B}: \mathrm{CH}_{3} \mathrm{CN}\end{array}$ & 330 \\
\hline B & $\begin{array}{l}\text { Benzoic acids } \\
\text { Catechins }\end{array}$ & $\begin{array}{l}\text { KINETEX-C18 column } \\
(4.6 \times 150 \mathrm{~mm}, 5 \mu \mathrm{m})\end{array}$ & $\begin{array}{c}\mathrm{A}: \mathrm{H}_{2} \mathrm{O} / \mathrm{CH}_{3} \mathrm{OH} / \mathrm{HCOOH} \\
(5: 95: 0.1 \mathrm{v} / \mathrm{v} / \mathrm{v}), \mathrm{pH}=2.5 \\
\mathrm{~B}: \mathrm{CH}_{3} \mathrm{OH} / \mathrm{HCOOH} \\
(100: 0.1 v / v)\end{array}$ & 280 \\
\hline
\end{tabular}

Elution conditions. Method A, gradient analysis: $5 \%$ B to $21 \%$ B in $17 \min +21 \%$ B in 3 min (2 min conditioning time); flow: $1.5 \mathrm{~mL} \min ^{-1}$; Method B, gradient analysis: $3 \% \mathrm{~B}$ to $85 \% \mathrm{~B}$ in $22 \mathrm{~min}+85 \% \mathrm{~B}$ in $1 \mathrm{~min}$ ( 2 min conditioning time); flow: $0.6 \mathrm{~mL} \mathrm{~min}{ }^{-1}$.

\subsection{Statistical Analysis}

All data were subjected to the statistical analysis for the normality and homoscedasticity through Saphiro-Wilk's test $(p>0.05)$ and Levene's test $(p<0.05)$, respectively. Mean comparisons were computed using the SPSS 25 software (version 25.0; SPSS Inc., Chicago, IL, USA). Correlations among the bioactive compounds of the two teas were calculated by Pearson's correlation coefficient test by means of PAST 4.03 software. Principal coordinate analysis (PCA) - Biplot was performed using the same software. Eigenvalues were calculated using a covariance matrix among 30 traits as input, and the two-dimensional PCA biplot was constructed.

\section{Results}

The total polyphenol content and the antioxidant activity (FRAP, DPPH, and ABTS assays) of both examined teas are reported in Table 2 .

Table 2. Total polyphenols, and antioxidant activity of Tea Compagnia del Lago (TCL) and Tea Camellia d'Oro (TCO). Data are presented as mean value \pm standard deviation.

\begin{tabular}{|c|c|c|c|c|c|c|}
\hline \multirow{3}{*}{ Tea Type } & \multirow{3}{*}{$\begin{array}{l}\text { Total Polyphenols } \\
\text { (mg GAE/100 g DW) }\end{array}$} & \multicolumn{5}{|c|}{ Antioxidant Activity } \\
\hline & & \multirow{2}{*}{$\begin{array}{c}\text { FRAP } \\
\left(\mathrm{mmol} \mathrm{Fe}^{2+} / \mathrm{kg}\right)\end{array}$} & \multicolumn{2}{|c|}{ DPPH } & \multicolumn{2}{|c|}{ ABTS } \\
\hline & & & $\begin{array}{c}(\mu \mathrm{mol} \mathrm{TE} / \mathrm{g} \\
\text { DW) }\end{array}$ & Inhibition \% & $\begin{array}{c}(\mu \mathrm{mol} \mathrm{TE} / \mathrm{g} \\
\text { DW) }\end{array}$ & Inhibition \% \\
\hline TCL & $8540.42 \pm 105.38$ & $25796.61 \pm 951.83$ & $302.35 \pm 10.4$ & 46.9 & $623.44 \pm 4.64$ & 94.3 \\
\hline $\mathrm{TCO}$ & $14918.91 \pm 222.31$ & $42758.86 \pm 933.85$ & $532.37 \pm 5.95$ & 61.2 & $881.08 \pm 1.81$ & 99.8 \\
\hline$p$ & $* *$ & $* * *$ & $* * *$ & & $* * *$ & \\
\hline
\end{tabular}

The statistical relevance is provided $\left(^{* *}=p<0.01 ;{ }^{* * *}=p<0.001\right)$.

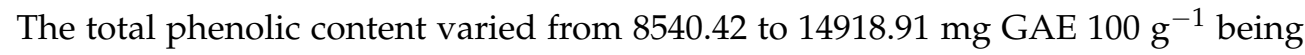
significantly higher in TCO. The antioxidant activity resulted higher for TCO rather than for TCL (42758.86 and $25796.61 \mathrm{mmol} \mathrm{Fe}^{2+} \mathrm{kg}^{-1}$ for the FRAP assay, respectively; 532.37 and $302.35 \mu \mathrm{mol} \mathrm{TE} \mathrm{g}^{-1} \mathrm{DW}$ for the DPPH assay, respectively; 881.08 and $623.44 \mu \mathrm{mol}$ TE $\mathrm{g}^{-1}$ DW for the ABTS assay, respectively).

In the TCO infusion, 13 compounds out of 13 were found by means of HPLC analysis, namely caffeic acid, chlorogenic acid, coumaric acid, ferulic acid, hyperoside, isoquercitrin, quercetin, quercitrin, rutin, ellagic acid, gallic acid, catechin, and epicatechin, while in TCL infusion, only 9 compounds out of 13 were found (chlorogenic acid, coumaric acid, ferulic acid, and quercetin were not detected) (Figure 2, Table 3). 

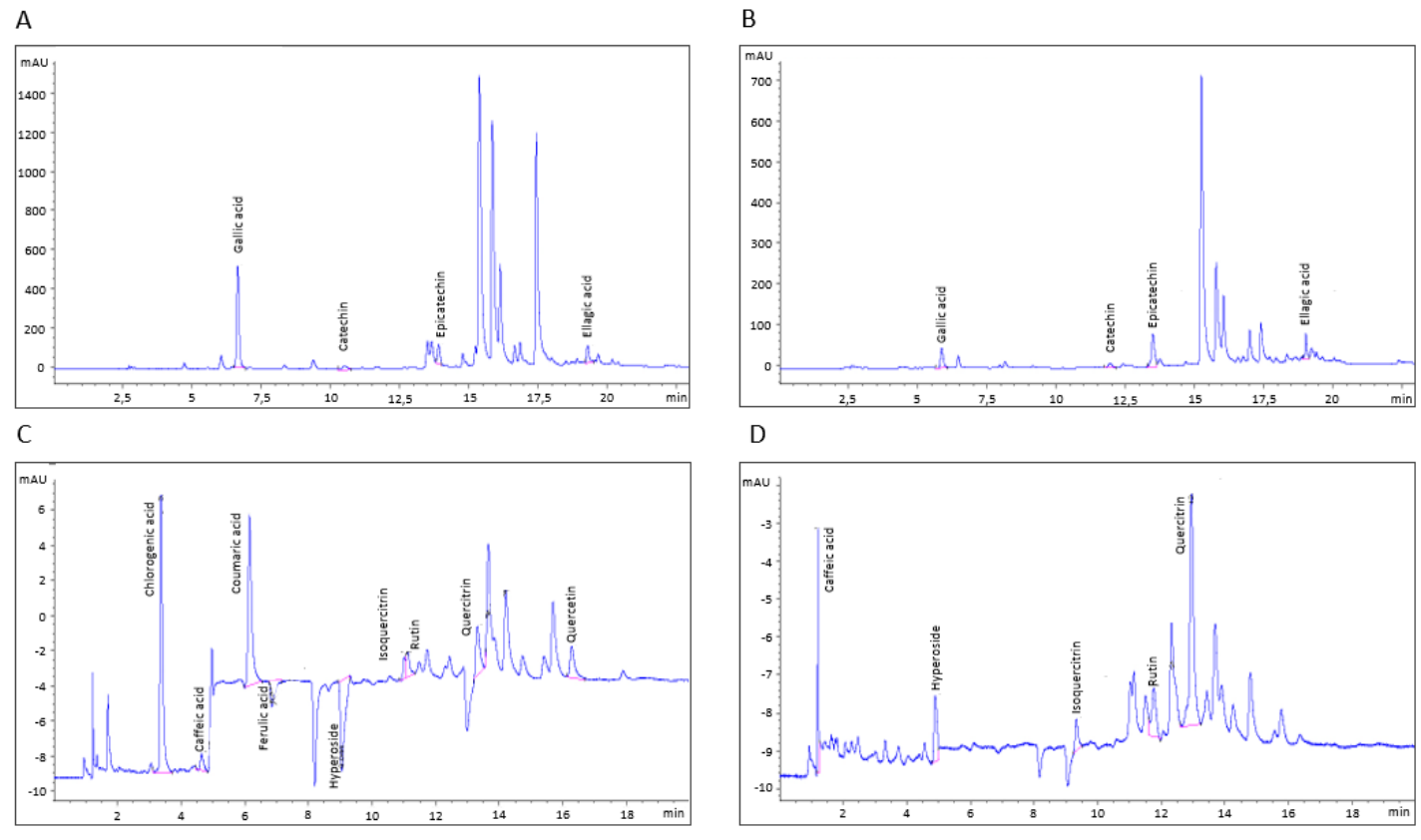

Figure 2. Chromatographic profile of benzoic acids and catechins (A), and cinnamic acids and flavonols (C) in TCO. Chromatographic profile of benzoic acids and catechins $(\mathbf{B})$ and cinnamic acids and flavonols (D) in TCL. TCO = Tea Camellia d'Oro. TCL = Tea Compagnia del Lago.

Table 3. Bioactive compounds in Tea Compagnia del Lago (TCL) and Tea Camellia d'Oro (TCO). Data are presented as

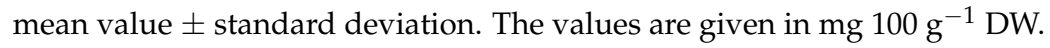

\begin{tabular}{|c|c|c|c|c|c|}
\hline \multirow{2}{*}{ Tea type } & \multicolumn{5}{|c|}{ Flavonols } \\
\hline & Hyperoside & Isoquercitrin & Quercetin & Quercitrin & Rutin \\
\hline TCL & $25.37 \pm 4.39$ & $35.46 \pm 2.60$ & - & $242.38 \pm 10.11$ & $44.66 \pm 3.93$ \\
\hline $\mathrm{TCO}$ & $28.24 \pm 4.30$ & $35.31 \pm 4.38$ & $388.28 \pm 95.47$ & $113.11 \pm 14.75$ & $42.32 \pm 4.19$ \\
\hline$p$ & $\mathrm{~ns}$ & ns & & $* * *$ & $\mathrm{~ns}$ \\
\hline \multirow{2}{*}{ Tea type } & \multicolumn{4}{|c|}{ Cinnamic acids } & \\
\hline & Caffeic acid & Chlorogenic acid & Coumaric acid & Ferulic acid & \\
\hline TCL & $42.57 \pm 6.67$ & - & - & - & \\
\hline $\mathrm{TCO}$ & $43.36 \pm 1.72$ & $612.25 \pm 37.58$ & $204.62 \pm 16.47$ & $57.85 \pm 13.32$ & \\
\hline$p$ & ns & & & & \\
\hline \multirow{2}{*}{ Tea type } & \multicolumn{2}{|c|}{ Benzoic acids } & \multicolumn{2}{|c|}{ Catechins } & \\
\hline & Ellagic acid & Gallic acid & Catechin & Epicatechin & \\
\hline TCL & $59.06 \pm 2.33$ & $42.39 \pm 2.37$ & $122.06 \pm 10.86$ & $770.39 \pm 21.06$ & \\
\hline $\mathrm{TCO}$ & $86.85 \pm 5.17$ & $803.88 \pm 56.99$ & $478.98 \pm 27.53$ & $735.84 \pm 89.76$ & \\
\hline$p$ & $* *$ & $* * *$ & $* * *$ & ns & \\
\hline
\end{tabular}

The statistical relevance is provided (ns $=$ non-significant; ${ }^{* *}=p<0.01 ;{ }^{* * *}=p<0.001$ ). -: compound not detected.

The two teas showed significant different contents in quercitrin $\left(242.38 \mathrm{mg} 100 \mathrm{~g}^{-1}\right.$ DW in TCL and $113.11 \mathrm{mg} 100 \mathrm{~g}^{-1} \mathrm{DW}$ in TCO). TCO and TCL showed significant different contents in cinnamic acids, with TCO being richer in these compounds than TCL. Benzoic acids and catechins were significantly higher in TCO than in TCL (except for epicatechin, which showed no significant differences in the two infusions). 
The phenolic content in both teas proved to be significantly correlated to their antioxidant activity (Figure 3), for the three methods used (FRAP, DPPH, ABTS). The phenolic content was also positively correlated $(p<0.05)$ to chlorogenic acid, coumaric acid, ferulic acid, quercetin, ellagic acid, gallic acid, and catechin content. Interestingly, chlorogenic acid was found to be negatively correlated $(p<0.05)$ to the quercitrin content, and this latter was negatively correlated to gallic acid too.

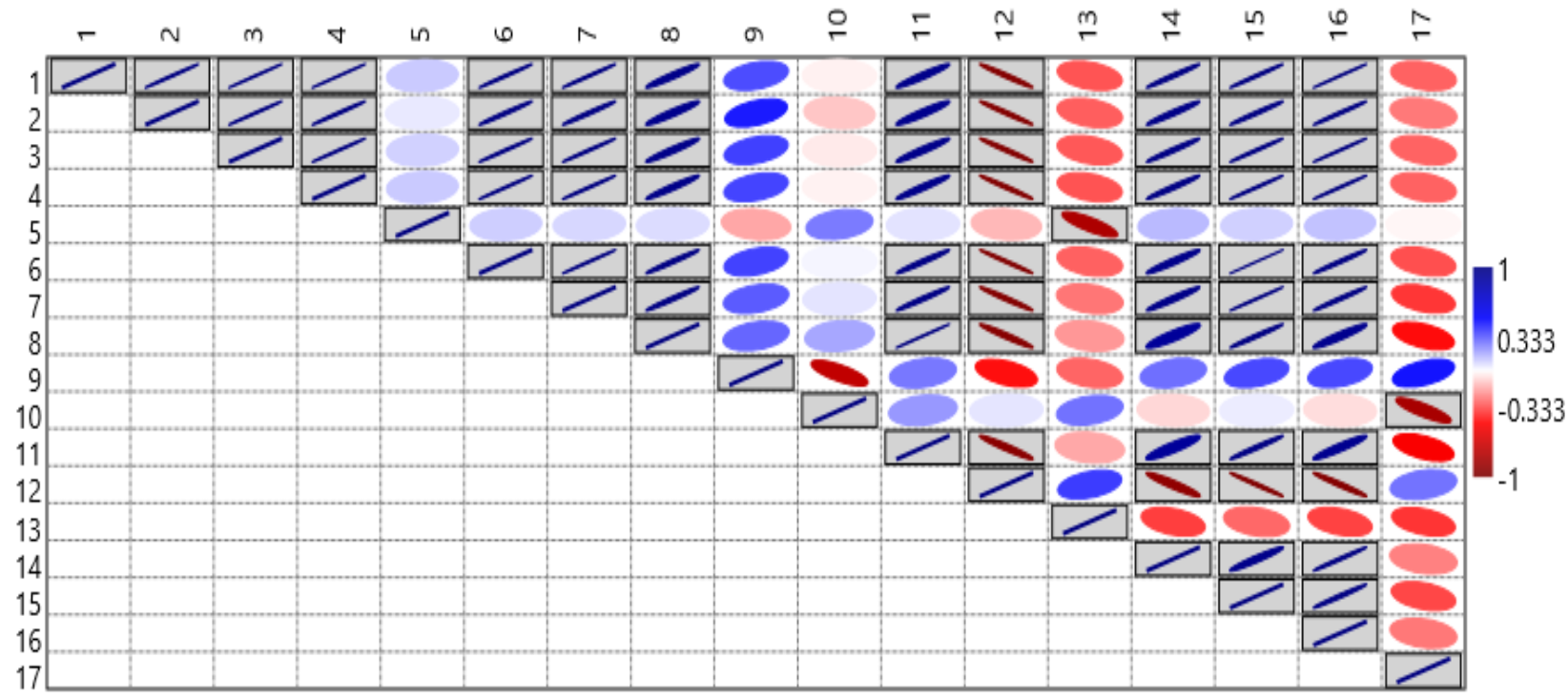

Figure 3. Pearson correlation among the bioactive compounds of Tea "Compagnia del Lago" (TCL) and Tea "Camelia d'Oro" (TCO). Boxed ellipses are significantly correlated $(p<0.05)$. Blue indicates positive correlation and red indicates negative correlation. The more the ellipse is compressed, the stronger the correlation. 1. Polyphenols; 2 . FRAP; 3 . DPPH; 4. ABTS; 5. caffeic acid; 6. chlorogenic acid; 7. coumaric acid; 8. ferulic acid; 9. hyperoside; 10. isoquercitrin; 11 . quercetin; 12. quercitrin; 13. rutin; 14. ellagic acid; 15. gallic acid; 16. catechin; 17. epicatechin.

The relationship between the studied parameters were evaluated through a PCA and represented in a two-dimensional PCA scatterplot (based on the first two principal components (PCs)) (Figure 4). As depicted, the first two PCs explained $77.8 \%$ of total variation. The first PC accounted for $62.2 \%$ and was positively correlated with polyphenols, antioxidant activity (FRAP, DPPH, and ABTS), caffeic acid, chlorogenic acid, coumaric acid, ferulic acid, hyperoside, isoquercitrin, quercetin, ellagic acid, gallic acid, and catechin; conversely, it was negatively correlated with quercitrin, rutin, and epicatechin. The second PC accounted for $15.6 \%$ and was positively correlated with chlorogenic acid, coumaric acid, ferulic acid, isoquercitrin, quercetin, quercitrin, rutin, gallic acid; conversely, it was negatively correlated with polyphenols, antioxidant activity (FRAP, DPPH, and ABTS), caffeic acid, hyperoside, ellagic acid, catechin, and epicatechin. The scatterplot showed that the two teas are clearly distinguished, confirming that TCO is mainly linked to almost all the detected bioactive compounds. In the opposite, TCL was correlated only to quercitrin, rutin, and epicatechin. 


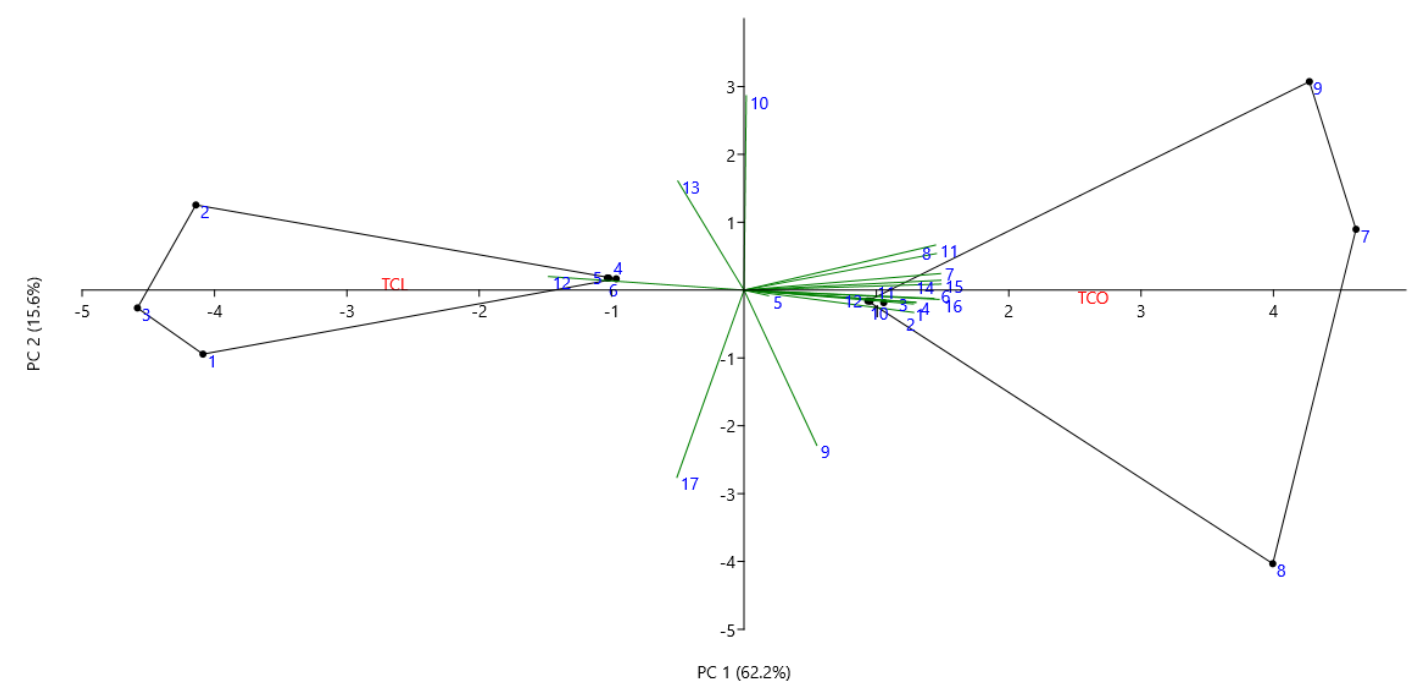

Figure 4. Principal component analysis (PCA)-biplot of Tea Compagnia del Lago (TCL) and Tea Camelia d'Oro (TCO), by means of the PAST 4.03 software. 1. Polyphenols; 2. FRAP; 3. DPPH; 4. ABTS; 5. caffeic acid; 6. chlorogenic acid; 7. coumaric acid; 8. ferulic acid; 9. hyperoside; 10. isoquercitrin; 11. quercetin; 12. quercitrin; 13. rutin; 14 . ellagic acid; 15. gallic acid; 16. catechin; 17. epicatechin.

\section{Discussion}

The Italian tea "Camelia d'Oro" (TCO) showed a total phenolic content (14918.91 mg GAE $100 \mathrm{~g}^{-1} \mathrm{DW}$ ) higher than the other green teas analyzed in similar studies. Cai et al. [37] purchased the green tea sample in a Chinese trade market, finding a total phenolic content of 13,600 mg GAE $100 \mathrm{~g}^{-1}$ DW. Mildner-Szkudlarz et al. [38] obtained Yunan green tea leaves in a special tea store, then ground leaves were extracted for $24 \mathrm{~h}$ using a $95 \%$ ethanol solution; the analysis showed a total phenolic content of 13,654 mg GAE $100 \mathrm{~g} \mathrm{~g}^{-1}$ DW. TCO even showed a higher phenolic content than the white tea analyzed by Zielinski et al. [39], which obtained a wide range: 3800-11,400 mg GAE $100 \mathrm{~g}^{-1} \mathrm{DW}$. Conversely, the "Compagnia del Lago" tea (TCL) showed a total phenolic content of $8540.42 \pm 105.38 \mathrm{mg}$ GAE $100 \mathrm{~g}^{-1} \mathrm{DW}$, lower than the previous studies' results. These data therefore might indicate that the cultivation and processing methods adopted by "La Camelia d'Oro" plantation promoted the accumulation of phenolic substances. However, Pérez-Burillo et al. [8] found a higher polyphenols content in commercial green tea in Spain, brewed in water for $7 \mathrm{~min}$ at $98^{\circ} \mathrm{C}$, obtaining a value of $1043 \pm 5 \mathrm{mg} \mathrm{GAE} \mathrm{L}^{-1}(\mathrm{TCO}=745.95 \mathrm{mg}$ $\mathrm{GAE} \mathrm{L}^{-1}$ ).

The antioxidant activity of the two teas, assessed with the DPPH, ABTS, and FRAP methods, confirmed the phenolic trend, being higher in TCO than in TCL. Regarding to the DPPH assay, TCO and TCL showed values of $532.37 \mu \mathrm{mol} \mathrm{TE} \mathrm{g}^{-1} \mathrm{DW}$ and 302.35 $\mu \mathrm{mol} \mathrm{TE} \mathrm{g}^{-1} \mathrm{DW}$ respectively, with an average inhibition percentage of $46.9 \%$ and $61.2 \%$ respectively. These results are higher than those published by Sirichaiwetchakoon et al. [3], who found an inhibition percentage of $41.46 \%$ for commercial green tea, purchased in a supermarket in the United Kingdom and prepared by boiling ground tea leaves in $80^{\circ} \mathrm{C}$ 1x phosphate buffered saline (PBS) for $5 \mathrm{~min}$. Conversely, Lv et al. [40] found a higher inhibition percentage in three black teas, ranging from $82.3 \%$ to $87.6 \%$. This is unusual, as many researchers suggest that green tea has more antioxidant activity than black tea [38], as green tea has no fermentation processing [41]. However, the same authors [40] found a lower inhibition percentage through the ABTS assay, ranging from 12.08 to $18.08 \%$, according to the black tea type. Conversely, in this study the ABTS assay confirmed the DPPH high values for both tea samples, ranging from $94.3 \%$ in TCL to $99.8 \%$ in TCO, thus confirming the highest antioxidant activity of green tea. 
A few works also evaluated the antioxidant activity by means of FRAP test, however, using different units of measurement, making it complex to compare the different values $[8,9]$.

The "Camelia d'Oro" tea (TCO) resulted to contain all the 13 bioactive compounds investigated, while the "Compagnia del Lago" tea (TCL) showed only 9. The major components identified in both Italian teas were quercetin, catechin, and epicatechin; in TCO also chlorogenic acid and gallic acid. Although not giving the single related values, Cai et al. [37] also found that catechin, epicatechin, and quercetin were the major types of phenolic compounds found in tea leaves.

The "Camelia d'Oro" tea (TCO) showed catechins (478.98 mg $\left.100 \mathrm{~g}^{-1} \mathrm{DW}\right)$ and epicatechins (735.84 mg $100 \mathrm{~g}^{-1} \mathrm{DW}$ ) values (Table 3) similar or higher than other green

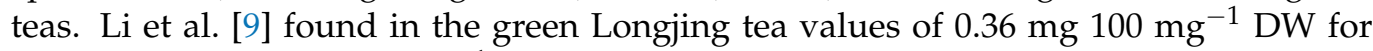
catechins and $0.90 \mathrm{mg} 100 \mathrm{mg}^{-1} \mathrm{DW}$ for epicatechins. Hyun et al. [25] found lower catechin values (ranging from 3.14 to $4.76 \mathrm{mg} \mathrm{g}^{-1} \mathrm{FW}$ ), but higher epicatechin values (ranging from 8.12 to $10.40 \mathrm{mg} \mathrm{g}^{-1} \mathrm{FW}$ ) than TCO. Conversely, the "Compagnia del Lago" tea (TCL)

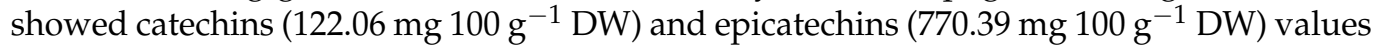
lower than the previous studies results.

It is noteworthy that the catechin content is highly correlated to the antioxidant activity measured with the three assays (FRAP, DPPH, and ABTS) (Table 3), as already found by Pérez-Burillo et al. [8], when comparing white and green teas. Catechins are known to have important human health benefits, due to their antioxidative, anti-inflammatory, anticarcinogenic, antidiabetic, and antimicrobial properties [34,41], and they may also help reduce the body mass index [42]. Quercetin shows antihypertensive effects, improving endothelial function, gene expression, and modulating cell signals [43], while coumaric acid has protective effects against carcinogenesis, atherosclerosis, oxidative cardiac damages and has anti-inflammatory effects [44].

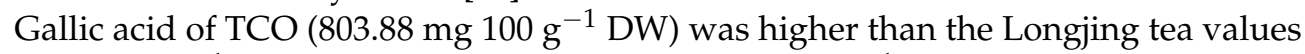
(0.07 mg $100 \mathrm{mg}^{-1} \mathrm{DW}$ ) [9], conversely TCL (42.39 mg $100 \mathrm{~g}^{-1} \mathrm{DW}$ ) values were lower.

Although not showing the single related values, Gorjanović et al. [45] showed the presence of ferulic and caffeic acids in green tea infusions, as they were detected in this study (Table 3).

Flavonols (hyperoside, isoquercitrin, quercitrin, rutin), chlorogenic acid, and ellagic acid were not frequently reported individually in other studies, but more as a single category of flavonols, cinnamic acids, and benzoic acids; they were almost all found in both the Italian teas.

Flavonols are health-promoted compounds [42] which can be largely found in green tea leaves [46], and chlorogenic acid has antioxidant, anti-inflammatory, anticancer, antilipidemic, antidiabetic, antihypertensive, and antineurodegenerative activities [47], thus these teas are a rich source of bioactive compounds.

As already observed by Li et al., Lv et al., and Tenore et al. [9,21,40], antioxidant activity was positively correlated with polyphenol content and, thus, with catechins content. The methods for the antioxidant activity analysis were also positively correlated with each other, as Zielinski et al. [39] observed.

\section{Conclusions}

This work investigated the content in bioactive compounds of two Italian teas, both cultivated in the Lake Maggiore District, in Piedmont. The results indicated that the two teas have different phenolic compositions, probably due to the different cultivation substrates or techniques.

The "Camelia d'Oro" tea (TCO) showed in general, higher bioactive compounds levels than the "Compagnia del Lago" tea (TCL).

However, both teas showed values in accordance with other studies' results, or even higher, confirming that they would be suitable to diversify the Italian growers' production with the $C$. sinensis cultivation. 
Author Contributions: Conceptualization, V.S.; methodology, M.C.; investigation, N.M.F., S.D., M.C.; data curation, N.M.F., M.C.; writing—original draft preparation, N.M.F.; writing-review and editing, M.C., S.D., V.S.; supervision, V.S.; project administration, V.S.; funding acquisition, V.S. All authors have read and agreed to the published version of the manuscript.

Funding: This research received no external funding.

Institutional Review Board Statement: Not applicable.

Informed Consent Statement: Not applicable.

Data Availability Statement: Not applicable.

Acknowledgments: Authors acknowledge Dario Donno for HPLC analysis, and the two nurseries, "La Camellia d'Oro" and "La Compagnia del Lago" for providing the two tea leaves.

Conflicts of Interest: The authors declare no conflict of interest.

\section{References}

1. Komes, D.; Horžić, D.; Belščak, A.; Ganić, K.K.; Vulić, I. Green tea preparation and its influence on the content of bioactive compounds. Food Res. Int. 2010, 43, 167-176. [CrossRef]

2. Ori, F.; Ma, J.; Gori, M.; Lenzi, A.; Chen, L.; Giordani, E. DNA-based diversity of tea plants grown in Italy. Genet. Resour. Crop Evol. 2017, 64, 1905-1915. [CrossRef]

3. Sirichaiwetchakoon, K.; Lowe, G.M.; Eumkeb, G. The Free Radical Scavenging and Anti-Isolated Human LDL Oxidation Activities of Pluchea indica (L.) Less. Tea Compared to Green Tea (Camellia sinensis). Biomed. Res. Int. 2020, 2020, 1-12. [CrossRef]

4. Koo, S.I.; Noh, S.K. Green tea as inhibitor of the intestinal absorption of lipids: Potential mechanism for its lipid-lowering effect. J. Nutr. Biochem. 2007, 18, 179-183. [CrossRef] [PubMed]

5. Xing, L.; Zhang, H.; Qi, R.; Tsao, R.; Mine, Y. Recent Advances in the Understanding of the Health Benefits and Molecular Mechanisms Associated with Green Tea Polyphenols. J. Agric. Food Chem. 2019, 67, 1029-1043. [CrossRef] [PubMed]

6. Sharangi, A.B. Medicinal and therapeutic potentialities of tea (Camellia sinensis L.)-A review. Food Res. Int. 2009, 42, 529-535. [CrossRef]

7. Jiang, X.; Liu, Y.; Li, W.; Zhao, L.; Meng, F.; Wang, Y.; Tan, H.; Yang, H.; Wei, C.; Wan, X.; et al. Tissue-Specific, DevelopmentDependent Phenolic Compounds Accumulation Profile and Gene Expression Pattern in Tea Plant [Camellia sinensis]. PLoS ONE 2013, 8, e62315. [CrossRef] [PubMed]

8. Pérez-burillo, S.; Giménez, R.; Ru, J.A.; Pastoriza, S. Effect of brewing time and temperature on antioxidant capacity and phenols of white tea: Relationship with sensory properties. Food Chem. 2018, 248, 111-118. [CrossRef]

9. Li, K.; Shi, X.; Yang, X.; Wang, Y.; Ye, C.; Yang, Z. Antioxidative activities and the chemical constituents of two Chinese teas, Camellia kucha and C. ptilophylla. Int. J. Food Sci. Technol. 2012, 47, 1063-1071. [CrossRef]

10. Food and Agriculture Organization of the United Nations. Current Market Situation and Medium Term Outlook. In Proceedings of the Twenty-Third Session of the Intergovernmental Group on Tea, Hangzhou, China, 17-20 May 2018; pp. 13-16.

11. FAO. Emerging Trends in Tea Consumption: Informing a Generic Promotion Process. In Proceedings of the Twenty-Third Session of the Intergovernmental Group on Tea, Hangzhou, China, 17-20 May 2018; pp. 1-9.

12. Food and Agriculture Organization of the United Nations. Developing futures and swap markets for tea. In Proceedings of the Twenty-Third Session of the Intergovernmental Group on Tea, Hangzhou, China, 17-20 May 2018; pp. 1-6.

13. Bhardwaj, P.; Kumar, R.; Sharma, H.; Tewari, R.; Ahuja, P.S.; Sharma, R.K. Development and utilization of genomic and genic microsatellite markers in Assam tea (Camellia assamica ssp. assamica) and related Camellia species. Plant Breed. 2013, 132, 748-763. [CrossRef]

14. Khan, N.; Mukhtar, H. Tea polyphenols for health promotion. Life Sci. 2007, 81, 519-533. [CrossRef] [PubMed]

15. Zheng, Q.; Li, W.; Zhang, H.; Gao, X.; Tan, S. Optimizing synchronous extraction and antioxidant activity evaluation of polyphenols and polysaccharides from Ya'an Tibetan tea (Camellia sinensis). Food Sci. Nutr. 2019, 8, 489-499. [CrossRef] [PubMed]

16. Heber, D.; Zhang, Y.; Yang, J.; Ma, J.E.; Henning, S.M.; Li, Z. Green tea, black tea, and oolong tea polyphenols reduce visceral fat and inflammation in mice fed high-fat, high-sucrose obesogenic diets. J. Nutr. 2014, 144, 1385-1393. [CrossRef]

17. Senanayake, S.P.J.N. Green tea extract: Chemistry, antioxidant properties and food applications-A review. J. Funct. Foods 2013, 5, 1529-1541. [CrossRef]

18. Karori, S.M.; Wachira, F.N.; Wanyoko, J.K.; Ngure, R.M. Antioxidant capacity of different types of tea products. African J. Biotechnol. 2007, 6, 2287-2296. [CrossRef]

19. Afzal, M.; Safer, A.M.; Menon, M. Green tea polyphenols and their potential role in health and disease. Inflammopharmacology 2015, 23, 151-161. [CrossRef]

20. Hayakawa, S.; Ohishi, T.; Miyoshi, N.; Oishi, Y.; Nakamura, Y.; Isemura, M. Anti-Cancer Effects of Green Tea Epigallocatchin-3Gallate and Coffee Chlorogenic Acid. Molecules 2020, 25, 4553. [CrossRef] 
21. Tenore, G.C.; Daglia, M.; Ciampaglia, R.; Novellino, E. Exploring the Nutraceutical Potential of Polyphenols from Black, Green and Exploring the Nutraceutical Potential of Polyphenols from Black, Green and White Tea Infusions-An Overview. Curr. Pharm. Biotechnol. 2015, 16, 265-271. [CrossRef] [PubMed]

22. Huo, C.; Dou, Q.P.; Chan, T.H. Synthesis of phosphates and phosphates-acetates hybrids of green tea polyphenol (-)epigallocatechine-3-gallate (EGCG) and its G ring deoxy analogs as potential anticancer prodrugs. Tetrahedron Lett. 2011, 52, 5478-5483. [CrossRef]

23. Kellogg, J.J.; Graf, T.N.; Paine, M.F.; McCune, J.S.; Kvalheim, O.M.; Oberlies, N.H.; Cech, N.B. Comparison of Metabolomics Approaches for Evaluating the Variability of Complex Botanical Preparations: Green Tea (Camellia sinensis) as a Case Study. J. Nat. Prod. 2017, 80, 1457-1466. [CrossRef]

24. Bramel, P.J.; Chen, L. A Global Strategy for the Conservation and Use of Tea Genetic Resources; Crop Trust: Bonn, Germany, 2019.

25. Hyun, D.Y.; Gi, G.Y.; Sebastin, R.; Cho, G.T.; Kim, S.H.; Yoo, E.; Lee, S.; Son, D.M.; Lee, K.J. Utilization of phytochemical and molecular diversity to develop a target-oriented core collection in tea germplasm. Agronomy 2020, 10, 1667. [CrossRef]

26. Camangi, F.; Stefani, A.; Bracci, T.; Minnocci, A.; Sebastiani, L.; Lippi, A.; Cattolica, G.; Santoro, A.M. Antiche Camelie Della Lucchesia; Sant'Anna, S.S., Ed.; ETS: Pisa, Italy, 2012; ISBN 978884673128-9.

27. Caser, M.; Berruti, A.; National, I.; Bianciotto, V.; National, I.; Devecchi, M. Floriculture and territory-The protection of the traditional Italian tipicity: The case of "La Camelia del Lago Maggiore (PGI)". Acta Hortic. 2018. [CrossRef]

28. Corneo, A.; Remotti, D. Camelie Dell'ottocento Nel Verbano; Regione Piemonte: Torino, Italy, 2000.

29. Freda, R.; Borrello, M.; Cembalo, L. Innovation in Floriculture When Environmental and Economics criteria are conflicting. Calitatea 2015, 16, 110-118.

30. Singleton, V.L.; Orthofer, R.; Lamuela-Raventós, R.M. Analysis of total phenols and other oxidation substrates and antioxidants by means of Folin- Ciocalteu reagent. Methods Enzymol. 1999, 299, 152-178.

31. Benzie, I.F.F.; Strain, J.J. The ferric reducing ability of plasma (FRAP) as a measure of "antioxidant power": The FRAP assay. Anal. Biochem. 1996, 239, 70-76. [CrossRef]

32. Wong, S.P.; Leong, L.P.; William Koh, J.H. Antioxidant activities of aqueous extracts of selected plants. Food Chem. 2006, 99, 775-783. [CrossRef]

33. Urbani, E.; Blasi, F.; Stella, M.; Claudia, S.; Cossignani, L. Investigation on secondary metabolite content and antioxidant activity of commercial saffron powder. Eur. Food Res. Technol. 2016, 242, 987-993. [CrossRef]

34. Caser, M.; Demasi, S.; Stelluti, S.; Donno, D.; Scariot, V.; Crocus sativus, L. Cultivation in Alpine Environments: Stigmas and Tepals as Source of Bioactive Compounds. Agronomy 2020, 10, 1473. [CrossRef]

35. Caser, M.; Demasi, S.; Victorino, M.M.I.; Donno, D.; Faccio, A.; Lumini, E.; Bianciotto, V.; Scariot, V. Arbuscular Mycorrhizal Fungi Modulate the Crop Performance and Metabolic Profile of Saffron in Soilless Cultivation. Agronomy 2019, 9, 232. [CrossRef]

36. Donno, D.; Mellano, M.G.; Riondato, I.; De Biaggi, M.; Andriamaniraka, H.; Gamba, G.; Beccaro, G.L. Traditional and Unconventional Dried Fruit Snacks as a Source of Health-Promoting Compounds. Antioxidants 2019, 8, 396. [CrossRef] [PubMed]

37. Cai, Y.; Luo, Q.; Sun, M.; Corke, H. Antioxidant activity and phenolic compounds of 112 traditional Chinese medicinal plants associated with anticancer. Life Sci. 2004, 74, 2157-2184. [CrossRef] [PubMed]

38. Mildner-Szkudlarz, S.; Zawirska-Wojtasiak, R.; Obuchowskij, W.; Goslinski, M. Evaluation of Antioxidant Activity of Green Tea Extract and Its Effect on the Biscuits Lipid Fraction Oxidative Stability. Sens. Food Qual. 2009, 74, 362-370. [CrossRef]

39. Zielinski, A.A.F.; Haminiuk, C.W.I.; Beta, T. Multi-response optimization of phenolic antioxidants from white tea (Camellia sinensis L. Kuntze) and their identification by LC-DAD-Q-TOF-MS/MS. LWT Food Sci. Technol. 2016, 65, 897-907. [CrossRef]

40. Lv, H.; Zhang, Y.; Shi, J.; Lin, Z. Phytochemical profiles and antioxidant activities of Chinese dark teas obtained by different processing technologies. Food Res. Int. 2017, 100, 486-493. [CrossRef]

41. Ananingsih, V.K.; Sharma, A.; Zhou, W. Green tea catechins during food processing and storage: A review on stability and detection. FRIN 2013, 50, 469-479. [CrossRef]

42. Demasi, S.; Caser, M.; Donno, D.; Enri, S.R.; Lonati, M.; Scariot, V. Exploring wild edible flowers as a source of bioactive compounds: New perspectives in horticulture. Folia Hortic. 2021, 33, 1-22. [CrossRef]

43. Xue, Z.; Wang, J.; Chen, Z.; Ma, Q.; Guo, Q.; Gao, X.; Chen, H. Antioxidant, antihypertensive, and anticancer activities of the flavonoid fractions from green, oolong, and black tea infusion waste. J. Food Biochem. 2018, 42. [CrossRef]

44. Cui, P.; Zhong, W.; Qin, Y.; Tao, F.; Wang, W.; Zhan, J. Characterization of two new aromatic amino acid lyases from actinomycetes for highly efficient production of p-Coumaric acid. Bioprocess Biosyst. Eng. 2020, 43, 1287-1298. [CrossRef]

45. Gorjanović, S.; Komes, D.; Pastor, F.T.; Belşçak-Cvitanović, A.; Pezo, L.; Heçimović, I.; Suz̧njević, D. Antioxidant capacity of teas and herbal infusions: Polarographic assessment. J. Agric. Food Chem. 2012, 60, 9573-9580. [CrossRef] [PubMed]

46. Lee, M.K.; Kim, H.-W.; Lee, S.-H.; Kim, Y.J.; Asamenew, G.; Choi, J.; Lee, J.-W.; Jung, H.-A.; Yoo, S.M.; Kim, J.-B. Characterization of catechins, theaflavins, and flavonols by leaf processing step in green and black teas (Camellia sinensis) using UPLC-DAD-QToF/MS. Eur. Food Res. Technol. 2019, 245, 997-1010. [CrossRef]

47. Santana-Gálvez, J.; Cisneros-Zevallos, L.; Jacobo-Velázquez, D.A. Chlorogenic Acid: Recent advances on its dual role as a food additive and a nutraceutical against metabolic syndrome. Molecules 2017, 22, 358. [CrossRef] [PubMed] 